\title{
DEVELOPMENT AND EVALUATION OF BILAYER TABLETS FOR IMMEDIATE AND CONTROLLED RELEASE OF METFORMIN HYDROCHLORIDE
}

\author{
RABLEE SAIKIA*, BHANU PRATAP SAHU \\ Girijananda Chowdhury Institute of Pharmaceutical Science, Azara, Guwahati 781017, Assam \\ Email: rableesaikia@gmail.com
}

Received: 22 May 2017, Revised and Accepted: 22 Jul 2017

\begin{abstract}
Objective: The purpose of this study was to develop and evaluate bi-layer tablets for the immediate and controlled release of Metformin Hydrochloride for effective treatment of type 2 Diabetes mellitus.

Methods: The immediate release layer was prepared by using super disintegrants like cross carmellose sodium, sodium starch glycolate and sustained release layer was prepared by using hydrophilic polymer like HPMC K 100 and PVP. Various proportions of super disintegrants and polymer were used to select the best formulation composition. Bilayer tablet of metformin was prepared by wet granulation method and was evaluated for physical characteristics like hardness, weight variation, and friability. In vitro release of drug was performed in USP type II dissolution test apparatus using phosphate buffer ( $\mathrm{pH} \mathrm{6.8)}$ as dissolution media and dissolution was continued for $9 \mathrm{~h}$ for the sustained release layer. For immediate release layer, readings were recorded in each $10 \mathrm{~min}$ time interval for the first $1 \mathrm{~h}$.
\end{abstract}

Results: From the obtained result it was found that all the formulations were within the limit of the standard. The hardness was found to be in the ranges from 5.1 to $5.5 \mathrm{~kg} / \mathrm{cm}^{2}$, weight variation was in the range $0.53 \%$ to $0.83 \%$, friability of all the formulations was within the range ( $<1 \%$ )and percentage of drug content was more than $97 \%$. The drug release of the tablet was in the range of $85 \%-91 \%$ in $9 \mathrm{~h}$.

Conclusion: From the result obtained, it is found that the formulation F6 satisfies all the criteria as sustained release tablet for the effective treatment of type 2Diabetes mellitus.

Keywords: Bilayer tablet, Metformin Hydrochloride, Type II diabetes mellitus, super disintegrants, Hydrophilic polymers, Wet granulation

(C) 2017 The Authors. Published by Innovare Academic Sciences Pvt Ltd. This is an open access article under the CC BY license (http://creativecommons.org/licenses/by/4.0/) DOI: http://dx.doi.org/10.22159/ijcpr.2017v9i5.22182

\section{INTRODUCTION}

Bilayer tablet is suitable for sequential release of two drugs in combination, separate two incompatible substances and also for sustained release tablet in which one layer is immediate release layer as initial dose and the second layer as a maintenance dose. Bi-layer tablets are prepared with one layer of the drug for immediate release when maximum relief needs to be achieved quickly with second layer design to release drug later as the second dose or in an extended release or for both immediate releases. It also avoids repeated administration of drug [1].

Diabetes is one of the most prevailing and advancing diseases in the world have affected $6.6 \%$ of the world population. Metformin hydrochloride is the most widely used oral Anti Diabetic drug in the world. Metformin shows high aqueous solubility and low cell membrane permeability. The usual dosage for Metformin is 250$500 \mathrm{mg}$ 3-4 times daily, up to a maximal of $2.5 \mathrm{~g} /$ day. The absolute bioavailability of Metformin hydrochloride is $50-60 \%$ and is having a short biological half-life of $6.2 \mathrm{~h}$. The use of Metformin therapy has the high incidence of gastrointestinal side effects. Frequent dosing schedule leading to high GI side effects and high daily dose makes its use unsuccessful, thus it is reasonable to formulate sustained release Metformin tablets to prolong its duration of action and to reduce total dose of drug administered as well as the incidence of adverse side effects, thus improving the patient compliance [2, 3]. In the present study, immediate release and sustained release bi-layer tablet (homogeneous type) of Metformin Hydrochloride were formulated to achieve better therapeutic profile by using sodium starch glycolate, cross carmellose sodium as a super disintegrant and HPMC K100, PVP as the hydrophilic polymer.

\section{MATERIALS AND METHODS}

\section{Materials}

Metformin hydrochloride was purchased from Yarrow Chem Product, Mumbai and dicalcium phosphate, microcrystalline cellulose, xanthum gum, sodium starch glycolate, cross carmellose sodium, HPMC K 100,
PVP, magnesium stearate, talc, eosin yellow, amaranth blue, potassium dihydrogen phosphate, sodium hydroxide were obtained from college laboratory at Girijananda Chowdhury Institute of Pharmaceutical Science.

\section{Methods}

The bilayer tablets of for immediate and controlled release of Metformin Hydrochloride were developed in two stages. Blends of the immediate release layer and sustained release layer of Metformin Hydrochloride were prepared separately.

\section{Preparation of immediate release layer}

For immediate release layer drug (125 mg), super disintegrants, diluents were weighed according to the formula and transferred to mortar and pestle and mixed thoroughly. Then in a beaker $10 \mathrm{ml}$ of water was taken and mixed with a binder (xanthum gum), which was used as a granulating liquid. Then the solution was added to the mixture, kneaded to form a wet mass. The wet mass was passed through sieve no. 20; wet granules were allowed to dry at $50{ }^{\circ} \mathrm{C}$, then again passed through sieve no. 40 to form dry granules. To the coarse, $5 \%$ fine, lubricants (magnesium stearate), glidants (talc) were added [4].

\section{Preparation of sustained release layer}

For sustained release layer drug (375 mg), a hydrophilic polymer (HPMC $\mathrm{K} 100$, PVP), diluents were weighed according to the formula and transferred to mortar and pestle and mixed thoroughly and wet granulation technique was followed as same as immediate release tablet. Here, in granulating liquid colour was also added. Finally, lubricants and talc are added to the granules and blended. The lubricated granules are manually fed into the die over the immediate release layer [4].

\section{Evaluation of the granules}

Preformulation

Preformulation studies were conducted for drug Metformin Hydrochloride. Preformulation characteristics like organoleptic properties, solubility, the melting point were determined [5]. 
Table 1: Formulation table of immediate release layer

\begin{tabular}{|c|c|c|c|c|c|c|c|}
\hline S. No. & Ingredients & F1 (mg) & F2 (mg) & F3 (mg) & F4 (mg) & F5 (mg) & F6 (mg) \\
\hline 1 & Metformin hydrochloride & 125 & 125 & 125 & 125 & 125 & 125 \\
\hline 2 & Sodium Starch Glycolate & $20(10 \%)$ & $20(10 \%)$ & $20(10 \%)$ & $10(5 \%)$ & $20(10 \%)$ & $20(10 \%)$ \\
\hline 3 & Cross Carmellose Sodium & - & - & - & $10(5 \%)$ & $20(10 \%)$ & - \\
\hline 4 & Xanthum Gum & 12 & 12 & 12 & 12 & 12 & 12 \\
\hline 5 & Dicalcium Phosphate & 17.5 & 17.5 & 17.5 & 17.5 & 8 & 17.5 \\
\hline 6 & Microcrystalline Cellulose & 17.5 & 17.5 & 17.5 & 17.5 & 7 & 17.5 \\
\hline 7 & Talc & 4 & 4 & 4 & 4 & 4 & 4 \\
\hline 8 & Magnesium Stearate & 4 & 4 & 4 & 4 & 4 & 4 \\
\hline 9 & Total weight & 200 & 200 & 200 & 200 & 200 & 200 \\
\hline
\end{tabular}

Table 2: Formulation table of sustained release layer

\begin{tabular}{|c|c|c|c|c|c|c|c|}
\hline S. No. & Ingredients & F1 (mg) & F2 (mg) & F3 (mg) & F4 (mg) & F5 (mg) & F6 (mg) \\
\hline 1 & Metformin hydrochloride & 375 & 375 & 375 & 375 & 375 & 375 \\
\hline 2 & HPMC K100 & $25(5 \%)$ & $50(10 \%)$ & $25(5 \%)$ & $25(5 \%)$ & $25(5 \%)$ & $50(10 \%)$ \\
\hline 3 & PVP & - & - & $25(5 \%)$ & $25(5 \%)$ & $25(5 \%)$ & $50(10 \%)$ \\
\hline 4 & Xanthum Gum & 30 & 30 & 30 & 30 & 30 & 30 \\
\hline 5 & Dicalcium Phosphate & 25 & 12.5 & 12.5 & 12.5 & 12.5 & - \\
\hline 6 & Microcrystalline Cellulose & 25 & 12.5 & 12.5 & 12.5 & 12.5 & - \\
\hline 7 & Talc & 10 & 10 & 10 & 10 & 10 & 10 \\
\hline 8 & Magnesium Stearate & 10 & 10 & 10 & 10 & 10 & 10 \\
\hline 9 & Eosin Yellow & q. $s$ & q. $s$ & q. $s$ & q. $s$ & q. $s$ & q. $s$ \\
\hline 10 & Amaranth Blue & q. $s$ & q. $s$ & q. $s$ & q. $s$ & q. $s$ & q. $s$ \\
\hline 11 & Total weight & 500 & 500 & 500 & 500 & 500 & 525 \\
\hline
\end{tabular}

\section{Pre compression characteristics}

Granules of all the formulations were subjected for various precompressional evaluations such as angle of repose, bulk and tapped density, Carr's index and Hausner's ratio [6].

\section{Post compression parameters}

\section{Weight variation test}

20 tablets were selected randomly from each batch, their weight was individual, collectively and the average weight was determined. The individual weight of the tablets was then compared to the average weight. The test requirements are met if not more than two of the individual weights deviate from the average weight by more than $5 \%$ and none deviates more than $10 \%$ [6].

\section{Friability}

The friability of tablets was determined using Roche fribilator to measure the mechanical strength of tablets. It is expressed in percentage (\%). 10 tablets from each batch were weighed separately (W initial) and placed in the fribilator. The fribilator was operated at $25 \mathrm{rpm}$ for $4 \mathrm{~min}$ or run up to 100 revolutions. The tablet was reweighed (Wfinal) and the \% friability (F) was then calculated for each batch by using the formula [6].

$$
\mathrm{F}=[\{(\text { Winitial })-(\text { Wfinal })\} /(\text { Winitial })] * 100
$$

\section{Hardness}

Five tablets were randomly picked and hardness of the tablets was determined using Monsanto hardness tester. It is expressed in $\mathrm{kg} / \mathrm{cm}^{2}$.

\section{Dissolution studies}

Drug release studies were done in phosphate buffer pH 6.8 as dissolution media by using USP type II dissolution apparatus (paddle type). The assembly is kept in a jacket vessel of water maintained at $37 \pm 0.5^{\circ} \mathrm{C}$ and $50 \mathrm{rpm}$ speed. The dissolution studied was carried out for $9 \mathrm{~h}$. For immediate release layer, $10 \mathrm{ml}$ of samples were collected at 10 min time interval for the first $1 \mathrm{~h}$ and for the sustained release layer, $10 \mathrm{ml}$ of samples were collected at 1 $\mathrm{h}$ time interval for rest $8 \mathrm{hs}$ and then filtered. It was replaced immediately with an equal amount of fresh buffer. The samples were then analyzed spectrophotometrically after suitable dilution at a wavelength of $230 \mathrm{~nm}$, taking phosphate buffer as blank [6].

\section{Drug content}

10 tablets of each formulation were powdered. Powder equivalent to $500 \mathrm{mg}$ of Metformin hydrochloride was weighed and transferred to $100 \mathrm{ml}$ volumetric flask, initially about $50 \mathrm{ml}$ of phosphate buffer 6.8 was added and the flask was shaken thoroughly and the volume was made up to $100 \mathrm{ml}$ with the buffer solution. The resulting solution was filtered. From this $1 \mathrm{ml}$ was taken and diluted to $100 \mathrm{ml}$ with buffer solution. From this $10 \mathrm{ml}$ was taken and diluted to $10 \mathrm{ml}$. From the resulting solution, drug content was estimated at $230 \mathrm{~nm}$ using UV spectrophotometer taking phosphate buffer as blank [6].

\section{Release kinetic}

The dissolution data obtained were fitted to various kinetic models like Zero order, First order, Higuchi, Korsemeyer Peppas to determine the release mechanism of prepared tablets [7].

\section{Drug excipient compatibility}

Studies of drug excipient compatibility represent an important phase in the pre-formulation stage of new dosage form development as it is most desirable for consistent efficacy, safety, and stability of drug product. The successful formulation of solid dosage form depends on careful selection of excipients which are added to facilitate administration, to promote consistent release and bioavailability of drug and protect it from degradation. Bruker FT-IR and Perkin Elmer DSC was used for thermal analysis of pure drug, excipients and formulations.

\section{RESULTS AND DISCUSSION}

\section{Pre-compression parameters}

Granules of all the formulations were subjected for various precompressional evaluations such as angle of repose, bulk and tapped density, Carr's index and Hausner's ratio. Results of all the precompressional parameters performed on granules are shown in table 3 and table 4 . The bulk density and tapped density of granules of both the layer were found to be in the range of 0.334 to 0.590 $\mathrm{gm} / \mathrm{ml}$ and 0.423 to $0.702 \mathrm{gm} / \mathrm{ml}$. The angle of repose varied from 23.32 to 38.3 which indicate good flow properties of the powder. While Compressibility index and Hausner's ratio were found in the range of 16.5 to 21.8 and 1.17 to 1.29 respectively. These values indicate that the powder mixture of all batches of formulation exhibited good flow properties. 


\section{Post compression parameters}

The results of physical evaluation of tablets are given in table 5 . The tablets of different batches were found uniform with respect to a hardness within the range of 5.1 to $5.5 \mathrm{~kg} / \mathrm{cm}^{2}$. Another measure of a tablet's strength is friability. Conventional compressed tablets that lose less than $1 \%$ of their weight are generally considered acceptable. Results of friability test were also found within the limit. In weight variation test, the pharmacopoeial limit for percentage deviation for tablets of more than $250 \mathrm{mg}$ is $\pm 5 \%$ and all the formulations were found to comply with the specifications given in I. P. for weight variation test. Weight variation of all tablets was found to be in the range of $0.53 \%$ to $0.83 \%$. Good uniformity in drug content was found among the formulations, and percentage of drug content was more than $97 \%$.

\section{Dissolution studies}

\section{In vitro drug dissolution study of immediate release layer}

The in vitro drug release data is shown in table 6 . The formulations F1-F3 and F6 having a composition of 10\% Sodium starch glycolate showed 24\% drug release. Formulation F4 showed 26.63\% (131 mg) drug release and Formulation F5 showed maximum drug release, showing up to $28 \%$ (140 $\mathrm{mg}$ ) of the total drug in first one $\mathrm{h}$. This may be due to the presence of $10 \%$ Sodium starch glycolate and $10 \%$ Cross carmellose sodium as a super disintegrant in F5. All the batches disintegrate within first one $\mathrm{h}$.

\section{In vitro drug dissolution study of sustained release layer}

For the sustained release layer of Metformin hydrochloride, the dissolution was carried up to $9 \mathrm{~h}$. The results showed that as the concentration of polymer increases the drug release is more controlled. F1 (5\%HPMC) and F2 (10\% HPMC) required $8 \mathrm{hr}$ to release $91 \%$ and $88 \%$ of its total drug respectively. F3, F4 and F5 (5\%HPMC and 5\%PVP) required $9 \mathrm{~h}$ for $87 \%$ drug release. And F6 $(10 \% \mathrm{HPMC}$ and $10 \% \mathrm{PVP})$ required $9 \mathrm{~h}$ to release $85 \%$ of its total drug from the tablet. The result of in vitro dissolution study showed that drug from all the batches was released in a controlled way.

\section{Kinetics and mechanism of release analysis}

After fitting into a different model, it was observed that all the formulations follow the First order and Higuchi release kinetics. And from the " $n$ " value of Krosemeyer Peppas of prepared formulations, shown in table 7 which was found to be in the range of 0.63 to 0.77 indicating erosion and diffusion controlled the release of the drug.

Table 3: Precompression evaluation of immediate release granules

\begin{tabular}{lllll}
\hline Formulation & $\begin{array}{l}\text { Bulk density } \\
\left(\mathbf{k g} / \mathbf{m}^{3}\right)\end{array}$ & $\begin{array}{l}\text { Tapped density } \\
\left(\mathbf{k g} / \mathbf{m}^{3}\right)\end{array}$ & $\begin{array}{l}\text { Angle of } \\
\text { repose }\left(\boldsymbol{\theta}^{\circ}\right)\end{array}$ & $\begin{array}{c}\text { Carr's index (\%) } \\
\text { Hausner's Ratio }\end{array}$ \\
\hline F1 (10\%SSG) & 0.402 & 0.482 & 38.3 & 16.5 \\
F4 (5\% SSG+5\%CCS) & 0.478 & 0.578 & 26.71 & 1.20 \\
F5 (10\% SSG+10\% CCS) & 0.590 & 0.702 & 23.32 & 16.53 \\
\hline
\end{tabular}

Table 4: Precompression evaluation of sustained release granules

\begin{tabular}{llllc}
\hline Formulation & Bulk density $\left(\mathbf{k g} / \mathbf{m}^{\mathbf{3}}\right)$ & Tapped density $\left(\mathbf{k g} / \mathbf{m}^{3}\right)$ & Angle of repose$\left(\boldsymbol{\theta}^{\circ}\right)$ & Carr's index $(\%)^{\text {Hausner's Ratio }}$ \\
\hline F1 (5\% HPMC) & 0.472 & 0.604 & 26.42 & 21.8 \\
F2 (10\% HPMC) & 0.487 & 0.584 & 28.2 & 1.28 \\
F3 (5\% HPMC+5\% PVP) & 0.449 & 0.579 & 36.87 & 1.19 \\
F6 (10\% HPMC+10\% & 0.334 & 0.423 & 25.17 & 22.4 \\
PVP) & & & & 20.80 \\
\hline
\end{tabular}

Table 5: Postcompression evaluation of tablets

\begin{tabular}{|c|c|c|c|c|}
\hline Formulation code & $\begin{array}{l}\text { Hardness } \\
\left(\mathrm{kg} / \mathrm{cm}^{-2}\right)\end{array}$ & $\begin{array}{l}\text { Friability } \\
(\%)\end{array}$ & $\begin{array}{l}\text { Weight variation } \\
\%\end{array}$ & $\begin{array}{l}\text { Drug content } \\
\%\end{array}$ \\
\hline F1 & 5.4 & 0.25 & 0.83 & 97.971 \\
\hline $\mathrm{F} 2$ & 5.2 & 0.39 & 0.69 & 99.628 \\
\hline F3 & 5.1 & 0.42 & 0.53 & 99.915 \\
\hline $\mathrm{F} 4$ & 5.5 & 0.75 & 0.63 & 99.239 \\
\hline F5 & 5.3 & 0.26 & 0.69 & 97.920 \\
\hline F6 & 5.3 & 0.58 & 0.68 & 99.526 \\
\hline
\end{tabular}

Table 6: In vitro drug release data

\begin{tabular}{|c|c|c|c|c|c|c|}
\hline Time (min) & F1 & F2 & F3 & F4 & F5 & F6 \\
\hline 10 & 11.572 & 12.185 & 11.887 & 15.759 & 14.059 & 11.035 \\
\hline 20 & 15.255 & 16.657 & 15.255 & 18.468 & 16.323 & 16.637 \\
\hline 30 & 20.918 & 18.788 & 20.918 & 21.067 & 18.149 & 19.107 \\
\hline 40 & 21.536 & 20.598 & 21.536 & 21.259 & 22.960 & 20.960 \\
\hline 50 & 23.089 & 22.450 & 23.089 & 24.389 & 25.663 & 22.706 \\
\hline 60 & 25.368 & 24.112 & 25.537 & 26.262 & 28.667 & 24.794 \\
\hline 120 & 32.054 & 28.501 & 32.631 & 30.501 & 33.841 & 27.435 \\
\hline 180 & 42.405 & 38.002 & 38.842 & 38.002 & 37.121 & 32.247 \\
\hline 240 & 52.482 & 48.823 & 47.857 & 45.033 & 46.766 & 40.926 \\
\hline 300 & 68.588 & 64.127 & 59.900 & 57.315 & 56.946 & 54.031 \\
\hline 360 & 76.197 & 75.183 & 70.932 & 68.364 & 66.427 & 65.376 \\
\hline 420 & 85.218 & 82.885 & 76.453 & 77.357 & 74.953 & 72.698 \\
\hline 480 & 91.711 & 88.558 & 85.849 & 84.378 & 82.849 & 80.571 \\
\hline 540 & & & 88.409 & 87.378 & 89.849 & 85.281 \\
\hline
\end{tabular}




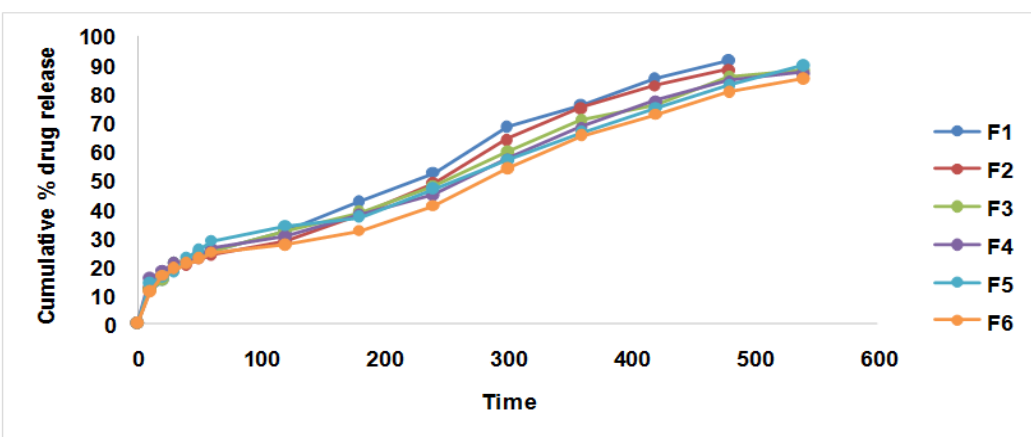

Fig. 1: Drug release study for bilayer metformin hydrochloride tablets in phosphate buffer pH 6.8

Table 7: Release kinetics parameter

\begin{tabular}{|c|c|c|c|c|c|c|c|}
\hline Model & Parameter & F1 & F2 & F3 & F4 & F5 & F6 \\
\hline \multirow[t]{2}{*}{ Zero Order } & $\mathrm{R}^{2}$ & 0.9519 & 0.9626 & 0.8860 & 0.8952 & 0.8836 & 0.9215 \\
\hline & $\mathrm{K}_{\mathrm{o}}$ & 0.209 & 0.201 & 0.177 & 0.174 & 0.173 & 0.165 \\
\hline \multirow[t]{2}{*}{ First Order } & $\mathrm{R}^{2}$ & 0.9671 & 0.9623 & 0.9735 & 0.9654 & 0.9592 & 0.9584 \\
\hline & $\mathrm{K}_{1}$ & 0.004 & 0.003 & 0.003 & 0.003 & 0.003 & 0.003 \\
\hline \multirow[t]{2}{*}{ Higuchi } & $\mathrm{R}^{2}$ & 0.9507 & 0.9354 & 0.9641 & 0.9543 & 0.9637 & 0.9345 \\
\hline & $\mathrm{KH}$ & 3.851 & 3.689 & 3.556 & 3.482 & 3.483 & 3.290 \\
\hline \multirow[t]{2}{*}{ Hixson Croswel } & $\mathrm{R}^{2}$ & 0.9821 & 0.9789 & 0.9783 & 0.9723 & 0.9626 & 0.9690 \\
\hline & $\mathrm{KHC}$ & 0.001 & 0.001 & 0.001 & 0.001 & 0.001 & 0.001 \\
\hline \multirow[t]{3}{*}{ Korsemayer Peppas } & $\mathrm{R}^{2}$ & 0.9920 & 0.9890 & 0.9840 & 0.9788 & 0.9817 & 0.9744 \\
\hline & $\mathrm{n}$ & 0.730 & 0.772 & 0.638 & 0.658 & 0.633 & 0.713 \\
\hline & KKP & 1.024 & 0.766 & 1.575 & 1.374 & 1.590 & 0.935 \\
\hline
\end{tabular}

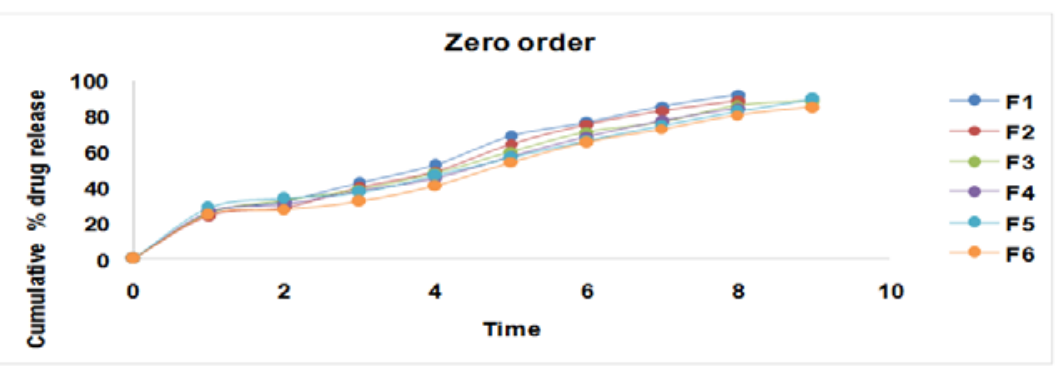

Fig. 2: Plot showing zero order kinetics of F1-F6

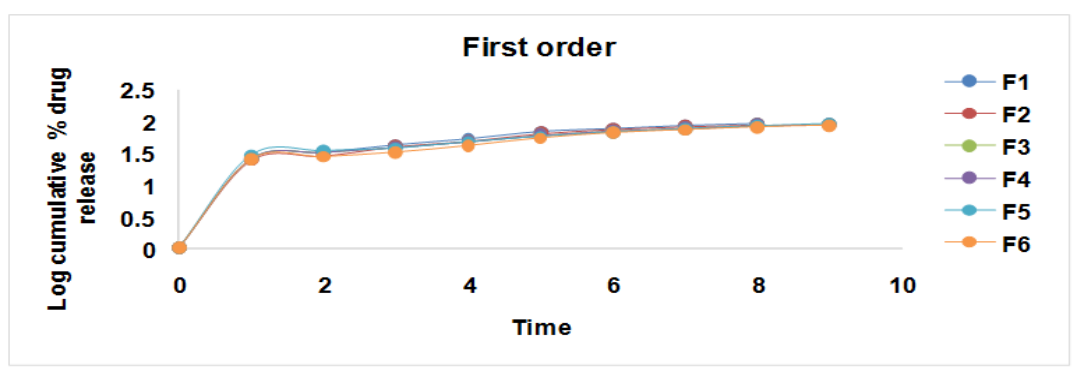

Fig. 3: Plot showing first order kinetic model of F1-F6

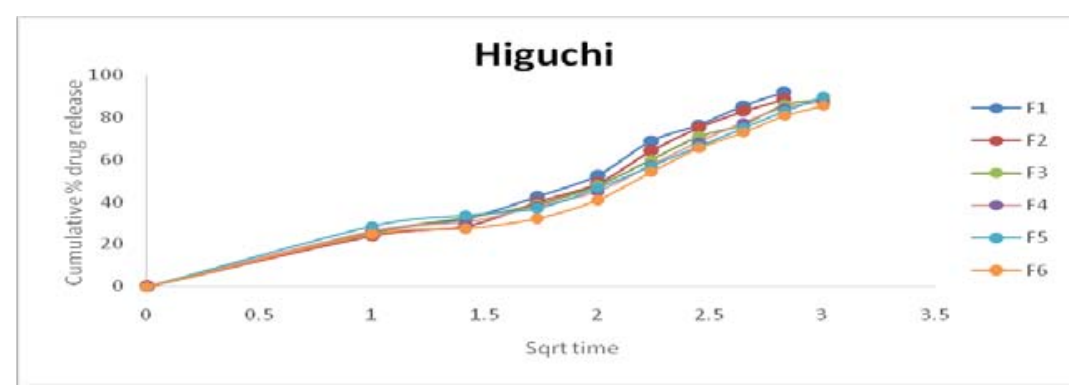

Fig. 4: Plot showing higuchi model of F1-F6 


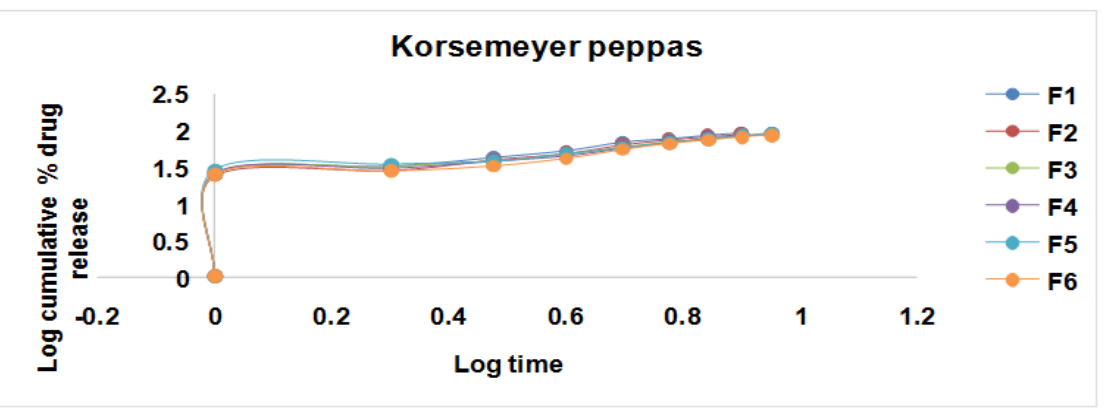

Fig. 5: Plot showing Korsmeyer-peppas model of F1-F6

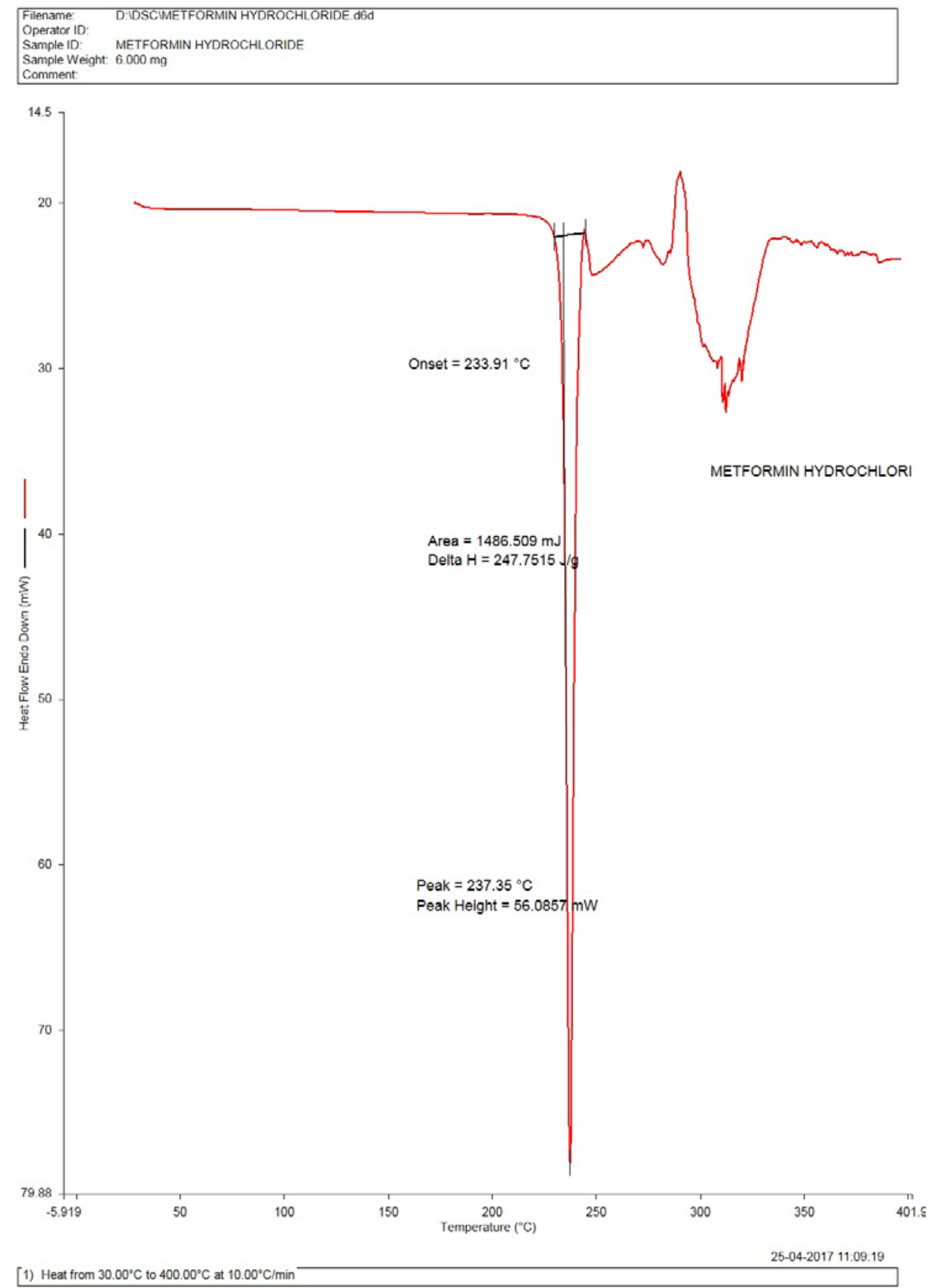

Fig. 6: DSC thermo gram of metformin hydrochloride 


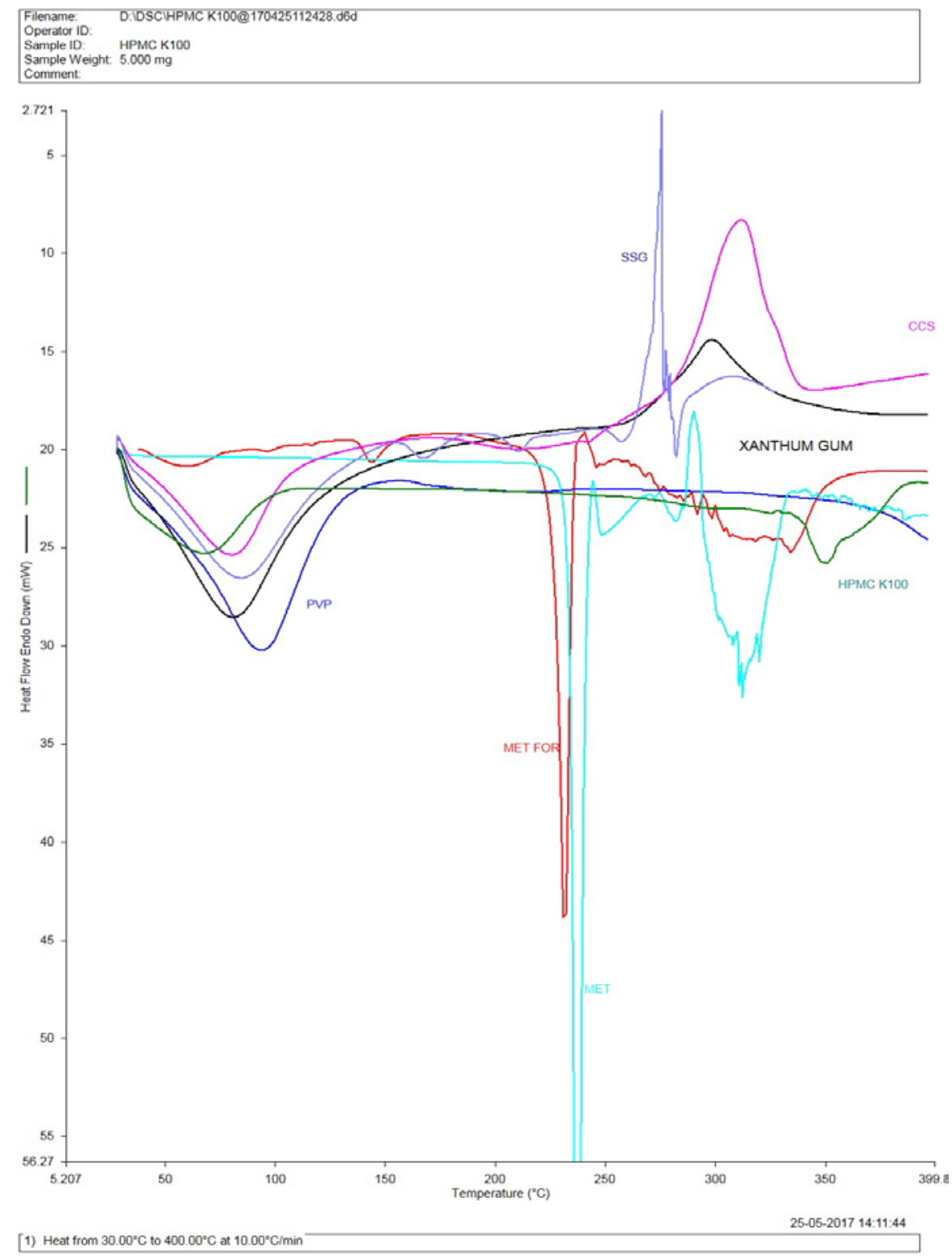

Fig. 7: DSC thermogram of Overlap (SSG-Sodium starch glycolate, CCS-Cross carmellose sodium, MET-metformin hydrochloride, MET FORmetformin hydrochloride formulation)

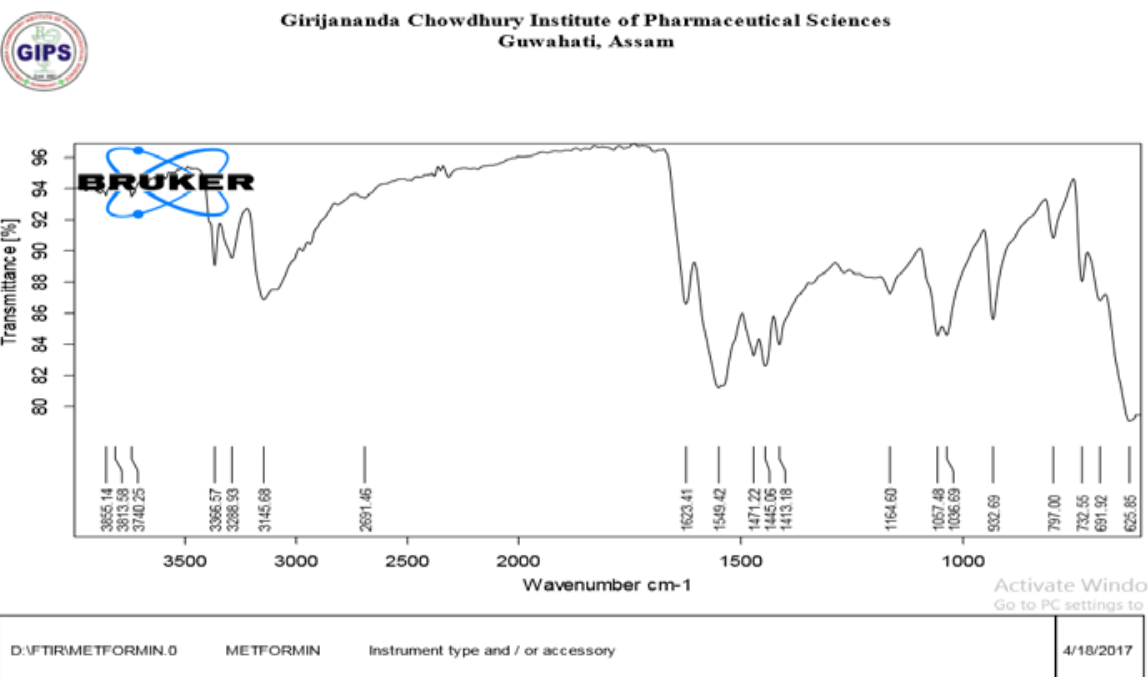

Fig. 8: IR spectrum of metformin hydrochloride 


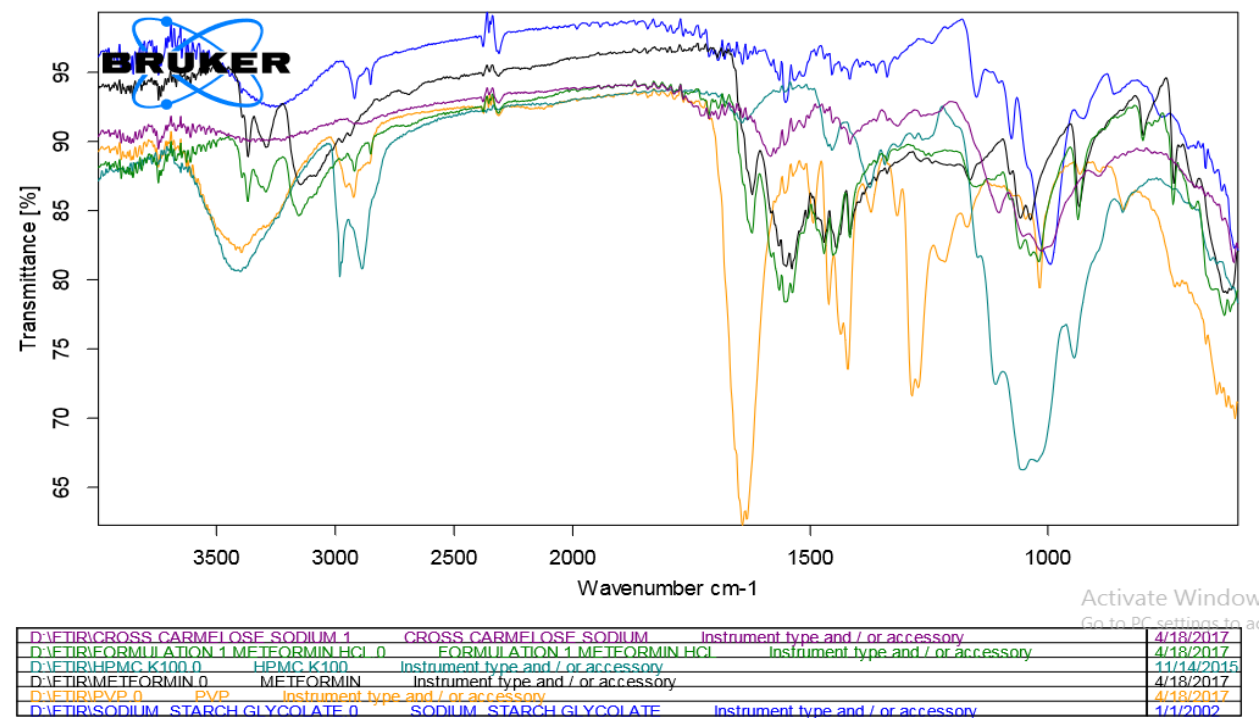

Fig. 9: IR spectrum of overlap

\section{CONCLUSION}

The present work involved formulation of bilayer tablets for the immediate and controlled release of Metformin hydrochloride using sodium starch glycolate and cross carmellose sodium as super disintegrant and HPMC K100, PVP as a retardant polymer.

The pre compression parameters and post compression parameters were obtained for all the formulations and were found to be within the acceptable limits. The drug-excipient compatibility studies confirmed that the both drugs are compatible with selected disintegrants sodium starch glycolate, cross carmellose sodium and polymer HPMC K100, PVP.

The drug release study from Metformin hydrochloride sustained release layer showed that as the concentration of the polymer increase the drug release decreases. The release of drug in the first $\mathrm{h}$ varies between $24 \%$ to $28 \%$ of total drug and the second layer drug release varies $85 \%$ to $91 \%$ of total drug contained in a controlled manner for $9 \mathrm{~h}$. The results reveal that with increase concentration of HPMC K100 and PVP retardation of drug release takes place. From the kinetic study, the drug release from drug layer follows the First order and Higuchi model. The " $n$ " values of Korsemeyer Peppas of the prepared formulation were found to in the range of 0.63 to 0.77 indicating erosion and diffusion controlled the release of the drug.

The drug release study tablet showed desired release profile for both layers. The first layer shows sufficient drug release within one $\mathrm{h}$ and the second layered showed controlled drug release for $9 \mathrm{~h}$. Hence the formulated Bilayer tablet can be used for effective and prolong management of Blood glucose level and it use for the treatment of Diabetes Mellitus 2. The study also reveals that sodium starch glycolate and cross carmellose sodium can be effectively used for the formulation of immediate release tablets and HPMC K100, PVP can be used as effective polymers for controlled release of the drug.

\section{CONFLICT OF INTERESTS}

Declare none

\section{REFERENCES}

1. Dandare MS, Sarage RD, Bhaskara S. Bilayer tablet: A Novel Approach for Immediate Release of Telmisartan and Hydrochlorothiazide Combination; 2012;4:3970-83.

2. Brito SR. Design and evaluation of sustained release bilayer tablet of metformin hydrochloride with metoprolol tartrate. Int J Novel Trends Pharm Sci 2011;1:10-7.

3. Rendle RD, Rutledge F, Hughes KJ, Heller J, Durham AE. Effects of metformin hydrochloride on blood glucose and insulin responses to oral dextrose in horses. Equine Veterinary J 2013;45:751-4

4. Chandira RM, Arafath AAMY, Bhowmik D, Jayakar B, Kumar KPS. Formulation and evaluation of bilayered floating tablets of metformin hydrochloride. Pharma Innovation 2012;1:26-39.

5. Shah RB, Tawakkul AK, Khan MA. Comparative evaluation of flow for pharmaceutical powders and granules. Am Assoc Pharm Sci PharmSciTech 2008;9:250-8.

6. Hadi MA, Pal N. Formulation and evaluation of sustained release matrix tablets of glimepiride based on a combination of hydrophilic and hydrophobic polymers. J Appl Pharm Sci 2012;2:101-7.

7. Shoaib MH. Evaluation of drug release kinetics from ibuprofen matrix tablets. Pakistan J Pharm Sci 2006;19:119-24.

\section{How to cite this article}

- $\quad$ Rablee Saikia, Bhanu Pratap Sahu. Development and evaluation of bilayer tablets for the immediate and controlled release of metformin hydrochloride. Int J Curr Pharm Res 2017;9(5):173-179. 